Vol.02/ No. 02

Pages: 84-91

https://www.irojournals.com/iroeea

DOI: https://doi.org/10.36548/jeea.2020.2.004

\title{
Investigation of Operational Efficiency using Stochastic Models for Electric propulsion in Ships
}

\author{
Nayana Shetty \\ Associate Professor, Department of Electrical and Electronics Engineering, \\ NMAMIT, Nitte, Udupi, Karnataka, India \\ Email id: nayanar401@gmail.com
}

\begin{abstract}
In various models of vehicle drive trains, issues such as improving electric propulsion reliability, environmental performance, and economic efficiency has been enabled by the recent developments in electric power engineering in terms of materials, equipment and technologies. The increasing requirements in ecological parameters, efficiency for fault tolerance and reliability, accurate selection of design features and type of electric propulsion drive as well as the limitations on the traction equipment weight and installation space are the important parameters for execution of the system approach. The automobile electric propulsion systems consisting of one or more traction motors and few generating elements and their operational efficiency are analysed by means of stochastic models. Aircrafts, hybrid cars, diesel-electric locomotives, arctic cargo ships and icebreakers are ideal platforms for implementation of the propulsion system. The load modes of traction electric motors, operational fuel consumption, energy output of thermal engines and several other probabilistic characters of operational processes and random factors that influence the simulation result accuracy cannot be evaluated using the deterministic approach.
\end{abstract}

Keywords: Ecological damage; Reliability; Efficiency; Ship electric propulsion; Markov-model;

\section{Introduction}

A systematic approach for various types of automobiles and implementation of an optimal propulsion system is an ever existing problem. Especially the ships that are designed for operation in the Arctic ice conditions are to be designed with precise solutions to avoid issues in the later stages. The specific operating parameters are estimated and analysed with stochastic models based on the methodology developed to enable efficient transportation of a ship in ice conditions with effective propulsion system. The varying significance and maximally probabilistic feature of the arctic ships aids in the evaluation and analysis of complex multi-criteria issues and in solving them [1]. An optimal propulsion system selection is the focus of this paper. The shipbuilding industry and electric propulsion systems are practically beginning to open with various research contributions towards this domain in the recent days. The cruise liners, icebreakers, ferries, bulk Arctic carriers and tankers have promising advantages due to the implementation of electric drives [2].

The traditional technological ideas and manufacturing experiences are the basis for the design of optimal propulsion system for several shipbuilding firms that make cargo ships that operate at the Arctic 
Vol.02/ No. 02

Pages: 84-91

https://www.irojournals.com/iroeea

DOI: https://doi.org/10.36548/jeea.2020.2.004

region and address specific issues in this domain [3]. Diverse propulsion systems are implemented in ships for scheduled operations to be performed with similar terms. The controllable pitch propeller, reducer, medium rotational speed diesel based diesel-reducer mechanical power drive (DRD), fixed pitch propeller and main electric motor based diesel-electric power drive (DED) created for ice conditions are represented in Figure 1 and Figure 2. The ship's economic performance, technical performance, successful future operation and decisive influence are characterised for the optimal choice of propulsion systems with their own pros and cons [4].

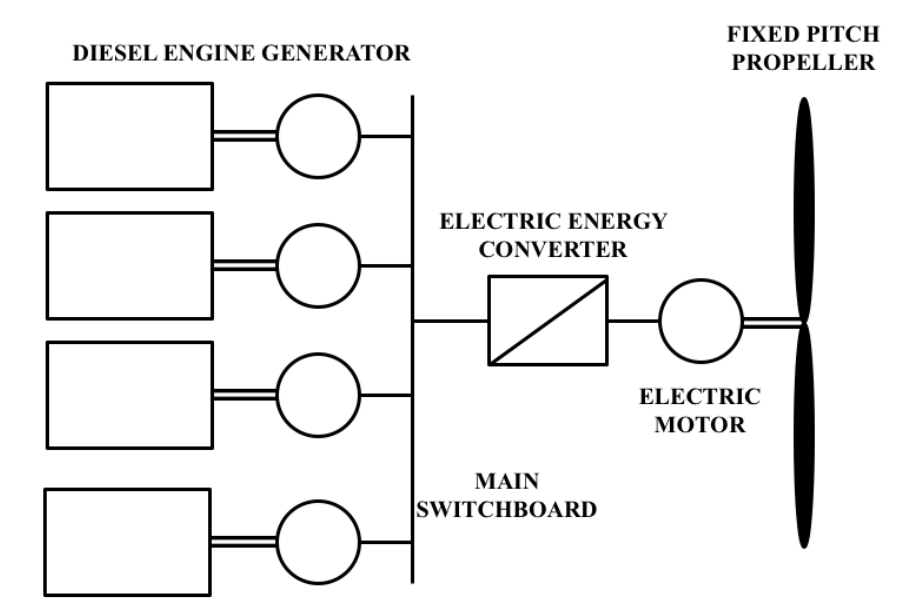

Figure 1:Electric power drive based on Diesel

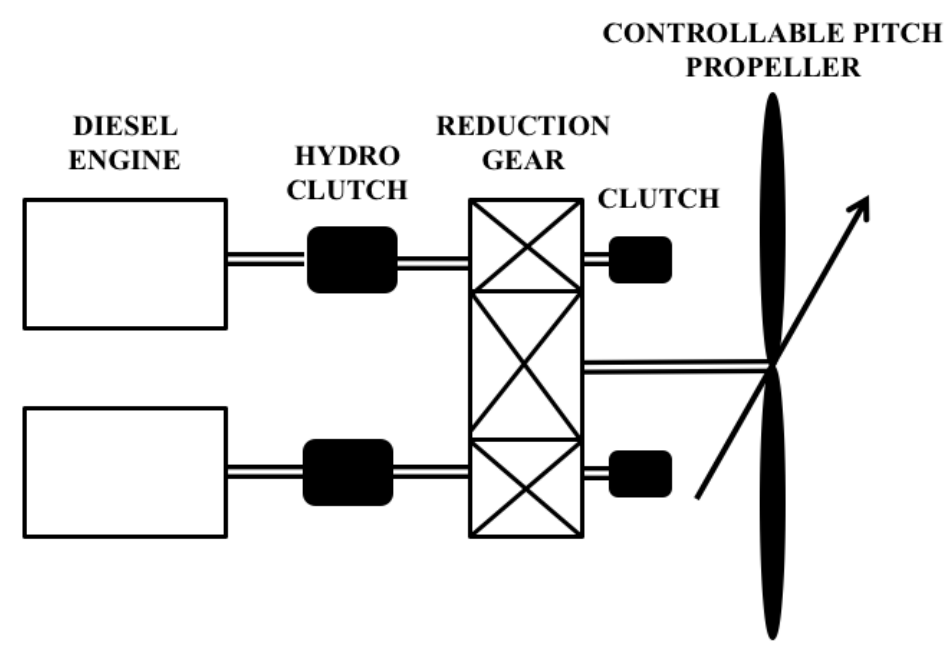

Figure 2: Diesel-reducer power drive 
Vol.02/ No. 02

Pages: 84-91

https://www.irojournals.com/iroeea

DOI: https://doi.org/10.36548/jeea.2020.2.004

Without considering the specific operational conditions, comparison of economic conditions such as life cycle costs, specific costs and capital expenditure instead of abstract parameters like technical excellence, and technical level coefficient are performed on a universal basis for the arctic operation ship propulsion system that affects the efficiency of the system [5]. The construction of the ship associated with the country of construction and date affects the technology and design parameters of the ship. Also, the limited ships availability in the arctic region impose great issues and complications. Hence it is essential to simulate the real time arctic ice conditions so as to understand the functioning of the ships by means of stochastic models to achieve accurate analysis and improved efficiency in the manufacturing process [6]. Hence, using the selected parameters of assessment, the stochastic models are developed and the statistical data is systemised and formalised for determining the real values of operating characteristics. Further, the arctic region ships and operational modes are statistically analysed.

\section{Comparative Analysis}

The technical performance and design vary significantly for various propulsion systems. Table 1 compares the DRPD and DEPD systems [7]. Direct current based electric propulsion system was built at the USSR Kherson shipbuilding factory in the DED Amguema based lead ship in the year 1962. 17 vessels were built between 1962 and 1975 of the same type [8]. The moral obsolescence of the DEDs in terms of low nominal efficiency, high capital cost, increasing weight and size at the end of the 1980s lead to the development of the DRDs and replacement of the DEDs in the ships. A shipyard at Finland built the diesel-reducer mechanical propulsion based DRD lead ship in the year 1982 [9]. 19 such vessels were built in the span of 5 years.

Table 1: Propulsion system comparison for two ships

\begin{tabular}{|l|c|c|}
\hline & DRPD & DEPD \\
\hline Knots, free water speed & 18,1 & 14,3 \\
\hline Screw count & 1 & 1 \\
\hline Cargo volume in tons & 15000 & 7900 \\
\hline Reducer & 1 & - \\
\hline Electric propulsion motor & - & 1 \\
\hline Rotational speed rpm & 560 & 810 \\
\hline Main diesel engine $\mathbf{k W}$ & $7720 \times 2$ & $1375 \times 4$ \\
\hline
\end{tabular}

Significant difference is observed in the statistical operational data between various shipping companies and vessels [10]. The DED based Amguema ships operate on supply trips during most of their 
operational time whereas the DRD based Norilsk operates as linear ships in a certain regional line of transport [11]. Further, 7 DRD based vessels and 3 DED based vessels are compared and the statistical data is analysed for operation in the arctic ice condition [12].

\section{Proposed Work}

The system approach is based exclusively on the objective decision of the number of uncertainties and the probabilistic nature of the problem complexity. The multicriteria analysis, cost benefit analysis and life cycle cost analysis are performed for various decision making techniques as a comparative study that provides their own advantages leading to effective assessment of the propulsion systems used in the marine environment and to create a universal technique that is efficient [13]. In the ice conditions, the required amount of cargo has to be delivered on a timely basis and trouble proof manner [14]. This criteria formed the Arctic ship's target function and the basis of the system approach. Usefulness and payment for usefulness are the two criteria based on which the parameters of the selected target function are divided. The damages and costs related to it are referred to as payment for usefulness. Hence they can be further grouped as non-financial and financial criterion [15].

While considering the Arctic cargo ship and its future operational conditions while considering the requirements based on the proposed technique, the productivity of transportation based on the "usefulness" criterion can be represented by the following expression:

$$
\begin{gathered}
\text { Productivity }=A S t_{d} \\
t_{d}=t_{o} r_{d}
\end{gathered}
$$

The transported cargo total in tons is represented by A, the speed of the ship in terms of knot is represented by $S$, the rate of driving time is represented by $r_{d}$, the driving time in terms of hours is given by $t_{d}$ and the operational time in hours is $t_{0}$. Further, the total cost of the ship including the operating and capital costs that provides the payment of usefulness, which is a complex criterion is represented by the following expression:

$$
\text { Total Cost }=\operatorname{Cost}_{C A P}+\operatorname{Cost}_{\operatorname{CoNST}}+\operatorname{Cost}_{F}+\operatorname{Cost}_{R A C}+\operatorname{Cost}_{E A C}
$$

Here, the capital costs are represented by Cost $_{\mathrm{CAP}}$; insurance, taxis, navigation fees, manning and so on contribute towards the fixed operating cost Cost ${ }_{\text {ConsT; }}$ oil and fuel operating cost Cost ; $_{\text {; }}$ Costs associated to reliability Cost ${ }_{\mathrm{RAC}}$ and costs associated to ecology Cost $\mathrm{EAC}_{\mathrm{C}}$. The varying degrees of the ship's 
Journal of Electrical Engineering and Automation (EEA) (2020)

Vol.02/ No. 02

Pages: 84-91

https://www.irojournals.com/iroeea

DOI: https://doi.org/10.36548/jeea.2020.2.004

operational condition helps in categorizing the values into two criteria that are generalized based on particular parameters. The external navigation conditions, fuel type, mode of energy generation and consumption are some of the operational factors that determine the operational performance of the system. Costs associated to ecology, costs associated to reliability, oil and fuel operating costs and the ship speed are the most informative parameters that provides details of the operating conditions. Markov models are created based on statistical data for generation and forecast of energy.

\section{Results and Discussion}

To construct a model of energy generation, the operational statistics for the 7 DRD based vessels and 3 DED based vessels are compared and the statistical data is analysed for operation in the arctic ice condition. This data is represented in the power distribution histogram represented in figure 3 along with the operational parameters. The Murmansk - Dudinka based arctic line is considered for analysis purpose and simulation of the ice conditions. The adhesion, compression ratio, characteristics of ice and influence of speed magnitude may be ignored under certain conditions of automatic navigation.

\begin{tabular}{|l|l|}
\hline \multicolumn{2}{|c|}{ Frequency Table } \\
\hline Class & Count \\
\hline $5-5.4$ & 8 \\
\hline $5.5-5.9$ & 10 \\
\hline $6-6.4$ & 13 \\
\hline $6.5-6.8$ & 12 \\
\hline $7-7.4$ & 15 \\
\hline $7.5-7.9$ & 13 \\
\hline $8-8.4$ & 11 \\
\hline $8.5-8.9$ & 12 \\
\hline $9-9.4$ & 2 \\
\hline $9.5-9.9$ & 0 \\
\hline & \\
\hline & \\
\hline \multicolumn{1}{|c|}{ Your Histogram } & 7.0375 \\
\hline Mean & 1.15141 \\
\hline Standard Deviation (s) & -0.03458 \\
\hline Skewness & -0.85532 \\
\hline Kurtosis & 5 \\
\hline Lowest Score & 9 \\
\hline Highest Score & 4 \\
\hline Distribution Range & 96 \\
\hline Total Number of Scores & 9 \\
\hline Number of Distinct Scores & 9 \\
\hline Lowest Class Value & 5 \\
\hline Highest Class Vaiue & 9.9 \\
\hline Number of Classes & 10 \\
\hline Class Range & 0.5 \\
\hline & \\
\hline
\end{tabular}

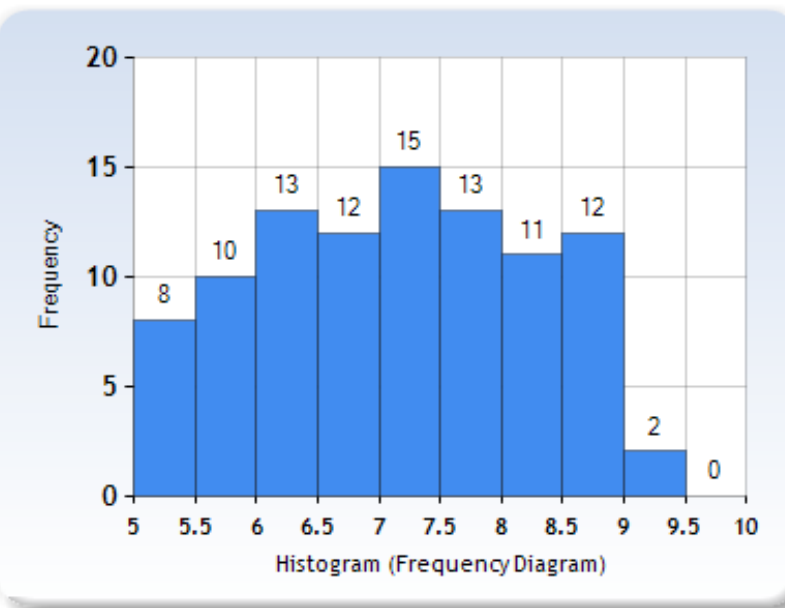

Figure 3: DED power distribution Histogram 
Journal of Electrical Engineering and Automation (EEA) (2020)

Vol.02/ No. 02

Pages: 84-91

https://www.irojournals.com/iroeea

DOI: https://doi.org/10.36548/jeea.2020.2.004

Figure 4 represents the power distribution statistical histogram of the DRD based ships. Weibull distribution is used for representing the parameters of power distribution to provide improved accuracy in the analysis results. Further, over $70 \%$ of the total operating time of the arctic cargo ships are spent in the arctic region of which a minimum of $60 \%$ of the overall operating time is under ice conditions. Based on all these factors, the operational parameters can be estimated and the operating modes of the ship can be determined. Out of the total operating time, the running time of the ship is over $37 \%$, cargo capacity utilization factor is around 0.5, DED power utilization factor is around 0.7, DRD power utilization factor is around 0.5 , the DED utilization rate speed is 0.57 and DRD utilisation rate speed is 0.52 .

In the operational conditions with real ice based scenarios, the arctic cargo ships offer competitive performance according to the comparative analysis in which the statistical data and selected parameters are compared which forms the basis for modelling the proposed technique. The Murmansk - Dudinka line is considered as the operational line for analysis of the navigational scenario of the DED and DRD based ships that carry cargo in the arctic ice condition. The operational efficiency of these ships are evaluated on a comparative basis. The adhesion, compression ratio, ice characteristics and influence on speed magnitude are challenging assessment parameters for the ship operating in solid ice conditions with autonomous navigation and purposeful movements offering reliability in character formalization of the propulsion of the ship.

\begin{tabular}{|l|l|}
\hline \multicolumn{2}{|c|}{ Frequency Table } \\
\hline Class & Count \\
\hline $0-0.74$ & 4 \\
\hline $0.75-1.49$ & 4 \\
\hline $1.5-2.24$ & 5 \\
\hline $2.25-2.99$ & 9 \\
\hline $3-3.74$ & 9 \\
\hline $3.75-4.49$ & 18 \\
\hline $4.5-5.24$ & 52 \\
\hline $5.25-5.99$ & 6 \\
\hline $6-6.74$ & 1 \\
\hline $6.75-7.49$ & 0 \\
\hline
\end{tabular}

\begin{tabular}{|l|l|}
\hline \multicolumn{2}{|c|}{ Your Histogram } \\
\hline Mean & 3.93287 \\
\hline Standard Deviation (s) & 1.31961 \\
\hline Skewness & -1.15349 \\
\hline Kurtosis & 0.60606 \\
\hline Lowest Score & 0.5 \\
\hline Highest Score & 6 \\
\hline Distribution Range & 5.5 \\
\hline Total Number of Scores & 108 \\
\hline Number of Distinct Scores & 15 \\
\hline Lowest Class Value & 0 \\
\hline Highest Class Value & 7.49 \\
\hline Number of Classes & 10 \\
\hline Class Range & 0.75 \\
\hline
\end{tabular}

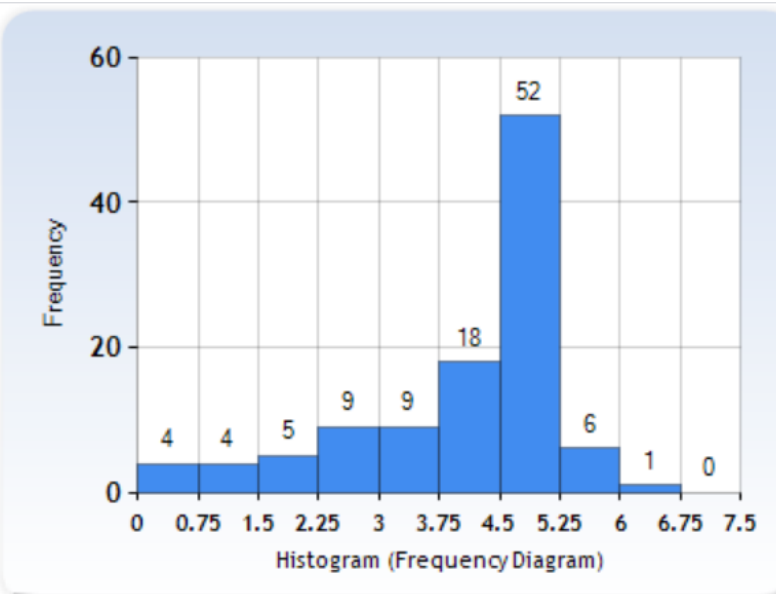


Journal of Electrical Engineering and Automation (EEA) (2020)

Vol.02/ No. 02

Pages: $84-91$

https://www.irojournals.com/iroeea

DOI: https://doi.org/10.36548/jeea.2020.2.004

\section{Conclusion}

Correction and regression analysis, Monte Carlo and other statistical tests, Markov model and similar stochastic modelling are used for solving the issues relevant to operational efficiency of the Arctic cargo ships using comprehensive comparative assessment techniques. However, under ice operating conditions, the operational efficiency of the ships may vary and demand different technical characteristics and design methodology. Monte-Carlo technique is used along with the Markov models for calculation of the costs related to repair and maintenance and the fuel which contributes towards the operational cost of the system as well as to simulate the real conditions of the transport facilities and their operational modes. Monte-Carlo technique is the most efficient technique for multi-factor regression used in the simulation of the transportation facilities under usefulness criteria.

A combination of MCA, CBA, LCC and their advantages is used for stochastic modelling in the proposed methodology for considering the functional and structural features of the vessel's propulsion system under specific operational conditions. Several propulsion systems are compared and the efficiency of operation of the ship can be improved by analysing the potential parameters and enabling navigation of the vessel through ice conditions using an optimum traction drive selection and objective decision making schemes. The detailed calculation and design is implemented on stochastic modelling technique and software based automated process used for selection of the components of the propulsion system predefining the power drive of the ship.

\section{References}

[1] Caprace, J. D., \& Rigo, P. (2009). Multi-criteria decision support for cost assessment techniques in shipbuilding industry. COMPIT'09, Budapest, 6-21.

[2] Abelson, P. (2010). Notes on Cost-Benefit Analysis Applied Economics. In Sydney (p. 157).

[3] A.S. Bykov, V.V. Bashaev, V.A. Malyshev, V.V. Romanovsky, "Electric propulsion systems of nuclear icebreakers", Sankt-Petersburg, Russia, Elmor, 2004, 319 p., (in Russian).

[4] Trivedi, K. S. (1982). Probability and statistics with reliability, queuing, and computer science applications (Vol. 13). Englewood Cliffs: Prentice-hall.

[5] Lisnianski, A., Frenkel, I., \& Ding, Y. (2010). Multi-state system reliability analysis and optimization for engineers and industrial managers. Springer Science \& Business Media.

[6] Bolvashenkov, I., \& Herzog, H. G. (2006). System approach to a choice of optimum factor of hybridization of the electric hybrid vehicle. In EVS 22 (pp. 1-12).

[7] Sodenkamp, M. (2013). Models, methods and applications of group multiple-criteria decision analysis. Operations Research, 181(1), 393-421. 
Journal of Electrical Engineering and Automation (EEA) (2020)

Vol.02/ No. 02

Pages: $84-91$

https://www.irojournals.com/iroeea

DOI: https://doi.org/10.36548/jeea.2020.2.004

[8] Gluch, P., \& Baumann, H. (2004). The life cycle costing (LCC) approach: a conceptual discussion of its usefulness for environmental decision-making. Building and environment, 39(5), 571-580.

[9] Skwirzynski, J. K. (Ed.). (2012). Electronic systems effectiveness and life cycle costing (Vol. 3). Springer Science \& Business Media.

[10] Pearce, D., Atkinson, G., \& Mourato, S. (2006). Cost-benefit analysis and the environment: recent developments. Organisation for Economic Co-operation and development.

[11] Argyrous, G. (2010). Cost-benefit analysis and multi-criteria analysis: Competing or complementary approaches. School of Social Sciences and International Studies, UNSW.

[12] Sodenkamp, M. (2013). Models, methods and applications of group multiple-criteria decision analysis. Operations Research, 181(1), 393-421.

[13] Wolfe, J., \& Roa, M. J. (2016). Advanced methods for tabulation of electrical loads during special modes of marine vessel operation. IEEE Transactions on Industry Applications, 53(1), 667-674.

[14] Kanellos, F. D., Prousalidis, J. M., \& Tsekouras, G. J. (2014). Control system for fuel consumption minimization-gas emission limitation of full electric propulsion ship power systems. Proceedings of the Institution of Mechanical Engineers, Part M: Journal of Engineering for the Maritime Environment, 228(1), 17-28.

[15] Frenkel, I., Bolvashenkov, I., Herzog, H. G., \& Khvatskin, L. (2017). Operational sustainability assessment of multipower source traction drive. In Mathematics Applied to Engineering (pp. 191-203). Academic Press.

\section{Biography}

Nayana Shetty, is working as associate professor in the Department of Electrical and Electronics Engineering NMAMIT, Nitte, Udupi, Karnataka, India. The author are of research are power electronics, instrumentation, electrical machines and drives, smart grids, power sources, renewable energy, intelligent systems, automation, control theory, circuits and systems, power systems, EHV, electric machines, future energy systems, autonomous and distributed energy systems, smart energy storage, and management. 